\title{
Association between ERCC1 and ERCC2 polymorphisms and breast cancer risk in a Chinese population
}

\author{
R. Zhao and M.F. Ying \\ Department of Pharmacy, Sir Run Run Shaw Hospital, School of Medicine, \\ Zhejiang University, Hangzhou, China \\ Corresponding author: M.-F. Ying \\ E-mail: miaofaying2@163.com \\ Genet. Mol. Res. 15 (1): gmr.15017263 \\ Received July 21, 2015 \\ Accepted October 26, 2015 \\ Published March 11, 2016 \\ DOI http://dx.doi.org/10.4238/gmr.15017263
}

\begin{abstract}
We conducted a case-control study to investigate the role of ERCC1 rs3212986 and ERCC2 rs13181 gene polymorphisms in the development of breast cancer. Between March 2012 and March 2014, a total of 242 newly diagnosed breast cancer patients with histopathologically confirmed primary breast cancer and 242 healthy controls were recruited. Genotyping of ERCC1 rs3212986 and ERCC2 rs13181 polymorphisms was carried out using polymerase chain reaction-restriction fragment length polymorphism analysis. Unconditional logistic regression analyses indicated that the TT genotype of rs3212986 was associated with a higher risk of breast cancer compared to that associated with the GG genotype $(\mathrm{OR}=2.05,95 \% \mathrm{Cl}=1.13-3.78)$. In dominant and recessive models, we found that the rs3212986 polymorphism was associated with increased risk of breast cancer, and the ORs were $1.50(95 \% \mathrm{Cl}=1.03-2.18)$ and $1.74(95 \% \mathrm{Cl}=1.01-3.11)$, respectively. In summary, we found that the ERCC1 rs3212986 polymorphism was associated with the development of breast cancer.
\end{abstract}

Key words: ERCC1; ERCC2; Polymorphism; Breast cancer 


\section{INTRODUCTION}

Breast cancer is by far the most common cancer among women and the leading cause of malignancy-related death in many countries. In 2012, 14.09 million people were newly diagnosed with cancer worldwide and approximately $21 \%$ of them were diagnosed with breast cancer according to the International Agency for Research on Cancer. It was also reported that breast cancer is the fifth leading cause of cancer-related deaths in the world (6.4\%) and accounted for nearly 200,000 deaths in developed countries. Sporadic forms of breast cancer account for approximately $95 \%$ of all cases, and the development of breast cancer is caused by genetic and environmental factors (Anderson, 1992; Claus et al., 1996; Martin and Weber, 2000; Robbins et al., 2010).

Efficient DNA repair is required for preventing the propagation of errors as well as for maintaining genomic stability. The repair of DNA damage involves more than 130 genes and several molecular pathways, including nucleotide excision repair (NER), base-excision repair, homologous recombination, and non-homologous end joining (Popanda et al., 2004). Thus, polymorphisms in DNA repair genes may cause defects in DNA repair, which may then influence an individual's susceptibility to cancer (Lunn et al., 1999). Excision repair cross-complementation group 1 (ERCC1) and ERCC2 are two DNA repair genes whose products are important in NER, and which lie on chromosome 19q13.3 (Smith et al., 2000). Recently, several studies have focused on the association between ERCC1 and ERCC2 variants (rs3212986 and rs13181, respectively) and breast cancer risks (Lee et al., 2005; Shen et al., 2006; Crew et al., 2007; Yang et al., 2013; Pei et al., 2014). However, the results were inconclusive, which may be due to limited sample sizes or ethnic differences in the study populations. Therefore, we conducted a case-control study to investigate the roles of ERCC1 rs3212986 and ERCC2 rs13181 gene polymorphisms in the development of breast cancer.

\section{MATERIAL AND METHODS}

\section{Study participants}

Between March 2012 and March 2014, a total of 275 newly diagnosed breast cancer patients with histopathologically confirmed primary breast cancer were recruited from Sir Run Run Shaw Hospital. In total, 242 patients agreed to participate into our study, and the participation rate was $88 \%$.

Healthy subjects $(\mathrm{N}=242)$ without breast cancer were randomly recruited from individuals who came to receive regular health check-ups at the Sir Run Run Shaw Hospital between March 2012 and March 2014. The control subjects were matched with breast cancer patients by age ( \pm 5 years).

Demographic and clinical information of breast cancer patients and control subjects was collected from a self-designed questionnaire and medical records, and included data such as age, menopausal status, tobacco smoking, tumor size, clinical stage, estrogen receptor (ER) status, and progesterone receptor (PR) status. All breast cancer patients and control subjects provided signed written informed consent before enrolment into the study. The protocol of the current study was approved by the Ethics Committee of Sir Run Run Shaw Hospital.

\section{Genotyping}

Peripheral blood samples $(2 \mathrm{~mL})$ were drawn from breast cancer patients and control 
subjects, and the blood samples were kept at $-80^{\circ} \mathrm{C}$ until use. Genomic DNA was extracted from the peripheral blood samples using the TIANamp Blood DNA Kit (Tiangen Biotech, Beijing, China). After extraction, genotyping of ERCC1 rs3212986 and ERCC2 rs13181 polymorphisms was carried out using polymerase chain reaction (PCR) coupled with restriction fragment length polymorphism (RFLP) analysis (PCR-RFLP). Primer sequences of ERCC1 rs3212986 and ERCC2 rs13181 polymorphisms were designed using the MassARRAY Assay Design 3.1 software (SEQUENOM, San Diego, CA, USA). The reaction conditions were as follows: $94^{\circ} \mathrm{C}$ for $4 \mathrm{~min} ; 35$ cycles of $94^{\circ} \mathrm{C}$ for $30 \mathrm{~s}, 60^{\circ} \mathrm{C}$ for $30 \mathrm{~s}$, and $72^{\circ} \mathrm{C}$ for $30 \mathrm{~s}$; and $72^{\circ} \mathrm{C}$ for $7 \mathrm{~min}$.

\section{Statistical analysis}

Differences in demographic and clinical characteristics between breast cancer patients and controls were analyzed by chi-squared $\left(\chi^{2}\right)$ tests. The distribution of genotypes of ERCC1 rs3212986 and ERCC2 rs13181 polymorphisms in controls was tested for deviation from HardyWeinberg equilibrium. We used $\chi^{2}$ tests to examine differences in genotypic and allelic distribution between breast cancer patients and controls. The odds ratios (ORs) and 95\% confidence intervals (Cls) were evaluated using logistic regression models adjusted for confounding factors. All statistical analyses were performed using the SPSS statistical package software, version 16.0 (SPSS Inc., Chicago, IL, USA).

\section{RESULTS}

The demographic and clinical characteristics of the breast cancer patients and controls are shown in Table 1. No significant differences were found between breast cancer patients and controls in terms of age, menopausal status, or tobacco smoking as determined by $\chi^{2}$ tests. Of the 242 breast cancer patients, $152(62.81 \%)$ had tumor size $\geq 2.0 \mathrm{~cm}, 177(73.14 \%)$ had clinical stage of I-II, 149 (61.57\%) were ER positive, and 128 (52.48\%) were PR positive.

\section{Table 1. Demographic and clinical characteristics of breast cancer patients and controls.}

\begin{tabular}{|c|c|c|c|c|c|c|}
\hline Characteristic & Patients (N) & $\%$ & Controls (N) & $\%$ & $\chi^{2}$ test & $P$ value \\
\hline \multicolumn{7}{|l|}{ Age, years } \\
\hline$<50$ & 106 & 43.80 & 107 & 44.21 & & \\
\hline$\geq 50$ & 136 & 56.20 & 135 & 55.79 & 0.008 & 0.93 \\
\hline \multicolumn{7}{|l|}{ Menopausal status } \\
\hline Pre-menopausal & 132 & 54.55 & 139 & 57.44 & & \\
\hline Post-menopausal & 110 & 45.45 & 103 & 42.56 & 0.41 & 0.52 \\
\hline \multicolumn{7}{|l|}{ Tobacco smoking } \\
\hline Non-smokers & 205 & 84.71 & 217 & 89.67 & & \\
\hline Ever-smokers & 37 & 15.29 & 25 & 10.33 & 2.66 & 0.10 \\
\hline \multicolumn{7}{|l|}{ Tumor size } \\
\hline$<2.0 \mathrm{~cm}$ & 90 & 37.19 & & & & \\
\hline$\geq 2.0 \mathrm{~cm}$ & 152 & 62.81 & & & & \\
\hline \multicolumn{7}{|l|}{ Clinical stage } \\
\hline$|-| \mid$ & 177 & 73.14 & & & & \\
\hline III-IV & 65 & 26.86 & & & & \\
\hline \multicolumn{7}{|c|}{ Estrogen receptor (ER) status } \\
\hline Negative & 93 & 38.43 & & & & \\
\hline Positive & 149 & 61.57 & & & & \\
\hline \multicolumn{7}{|c|}{ Progesterone receptor (PR) status } \\
\hline Negative & 115 & 47.52 & & & & \\
\hline Positive & 128 & 52.48 & & & & \\
\hline
\end{tabular}


The genotype distributions of ERCC1 rs3212986 and ERCC2 rs13181 polymorphisms were found to be in Hardy-Weinberg equilibrium in the controls, and the P values for ERCC1 rs3212986 and ERCC2 rs13181 were 0.47 and 0.24, respectively (Table 2). However, we found that there was a significant difference in the genotype distributions of ERCC1 rs3212986 between breast cancer patients and controls $\left(\chi^{2}=6.88, P=0.03\right)$. Unconditional logistic regression analyses indicated that the TT genotype of rs3212986 was associated with an increased risk of breast cancer compared to that of the $\mathrm{GG}$ genotype $(\mathrm{OR}=2.05,95 \% \mathrm{Cl}=1.13-3.78)$. In dominant and recessive models, we found that the rs3212986 polymorphism was associated with increased breast cancer risk, and the ORs were $1.50(95 \% \mathrm{Cl}=1.03-2.18)$ and $1.74(95 \% \mathrm{Cl}=1.01-3.11)$, respectively. However, we did not find a significant association between ERCC2 rs13181 polymorphism and the development of breast cancer in codominant, dominant, or recessive models.

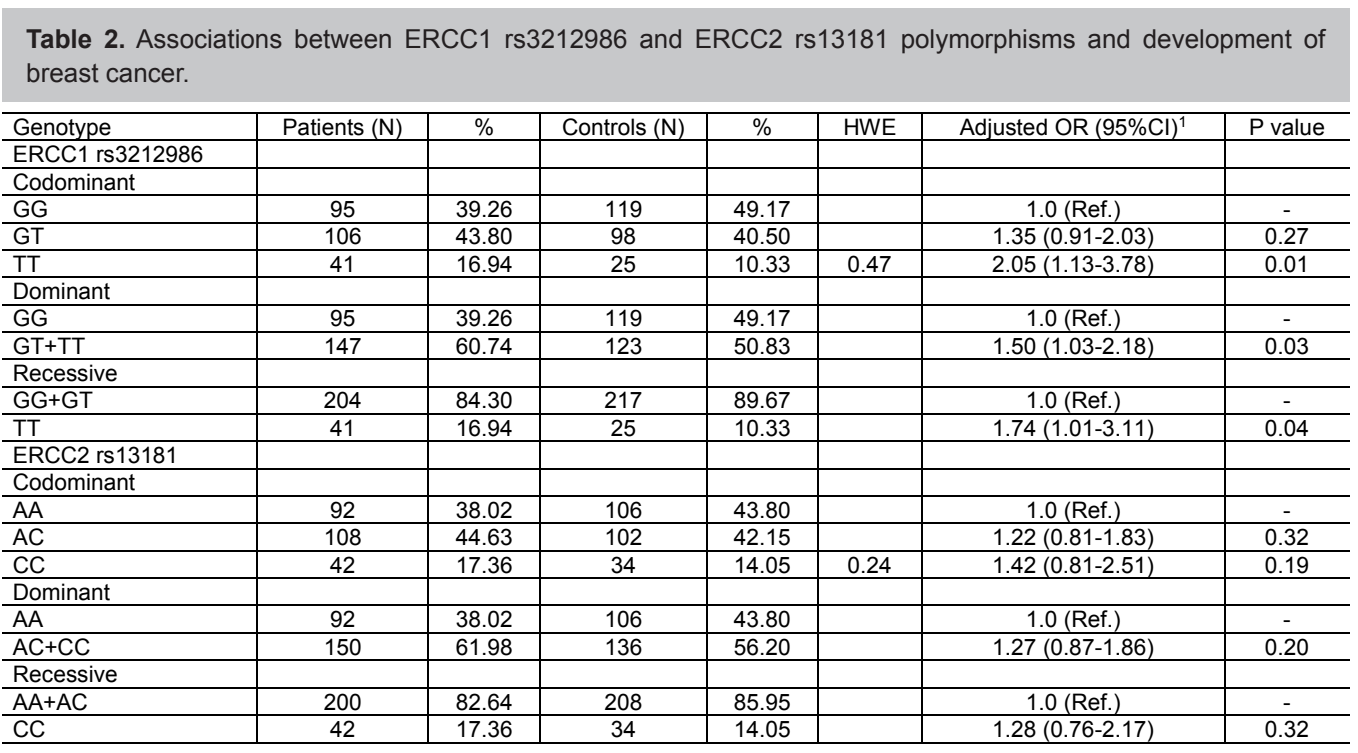

${ }^{1}$ Adjusted for age, menopausal status, and tobacco smoking.

\section{DISCUSSION}

Breast cancer is caused by many environmental and genetic factors, such as exposure to tobacco carcinogens, metallic compounds, and genetic polymorphisms. Genetic factors that influence DNA damage repair capacity may be important endogenous factors influencing the development of breast cancer. Specifically, polymorphisms in DNA repair genes can affect DNA repair efficiency, and thus influence the development of breast cancer. In the present study, we evaluated the role of ERCC1 rs3212986 and ERCC2 rs13181 polymorphisms in breast cancer risk, and found that the ERCC1 rs3212986 polymorphism was associated with an increased risk of breast cancer in a Chinese population.

Many epidemiologic studies have investigated the impact of the ERCC1 rs3212986 polymorphism in the risk of several cancers including glioma, breast cancer, lung cancer, and colorectal cancer (Adel Fahmideh et al., 2014; Zhu et al., 2014; Hou et al., 2014). For example, Adel Fahmideh et al. (2014) conducted a meta-analysis of 27 case-control studies and assessed 
the association between DNA repair gene polymorphisms and risk of glioma, and found that the ERCC1 rs3212986 polymorphism may significantly increase the risk of glioma. Interestingly, Zhu et al. (2014) conducted a meta-analysis of 16 case-control studies, which demonstrated that there was no association between the ERCC1 rs3212986 polymorphism and lung cancer. However, Hou et al. (2014) conducted a 1:1 matched case-control study in a Chinese population, and found that the ERCC1 rs3212986 polymorphism was correlated with an increased risk of colorectal cancer. Taken together, these previous findings suggest that the ERCC1 rs3212986 polymorphism has a role in the development of certain cancers, which may be dependent on the study population.

Regarding the association between the ERCC1 rs3212986 polymorphism and breast cancer development, five prior studies have reported on their association (Lee et al., 2005; Shen et al., 2006; Crew et al., 2007; Yang et al., 2013; Pei et al., 2014). First, Lee et al. (2005) conducted a study in a Korean population, and reported that the ERCC1 rs3212986 polymorphism was associated with breast cancer risk. Pei et al. (2014) later found that the rs3212986 polymorphism was associated with an increased risk of breast cancer in a Chinese population. However, some inconsistencies have been reported. For example, Shen et al. (2006) demonstrated that the ERCC1 rs3212986 polymorphism could not predict the breast cancer development. Moreover, Yang et al. (2013) did not find an association between the ERCC1 rs3212986 polymorphism and breast cancer. In the current study, we found that the ERCC1 rs3212986 polymorphism was associated with an increased risk of breast cancer in a Chinese population. The inconsistencies of the aforementioned studies may be due to differences in ethnicities, selection of patients, and/or sample size.

There were two limitations in the present study. First, there may have been selection bias due to the hospital-based design, although the age matching between patients and controls could have reduced this bias. Second, the sample size of patients and controls was relatively small, which may have limited the statistical power to find differences between the groups. Therefore, studies with larger sample sizes are needed to confirm our results.

In summary, we found that the ERCC1 rs3212986 polymorphism was associated with the development of breast cancer. Future studies with larger sample sizes may help to further elucidate the impact of the ERCC1 rs3212986 polymorphism in the risk of breast cancer.

\section{Conflicts of interest}

The authors declare no conflict of interest.

\section{ACKNOWLEDGMENTS}

We thank the help from staffs of Sir Run Run Shaw Hospital for collecting the blood samples from subjects.

\section{REFERENCES}

Adel Fahmideh M, Schwartzbaum J, Frumento P and Feychting M (2014). Association between DNA repair gene polymorphisms and risk of glioma: a systematic review and meta-analysis. Neuro. Oncol. 16: 807-814. http://dx.doi.org/10.1093/neuoncl $\underline{\text { nou003 }}$

Anderson DE (1992). Familial versus sporadic breast cancer. Cancer 70: 1740-1746. http://dx.doi.org/10.1002/10970142(19920915)70:4+<1740::AID-CNCR2820701615>3.0.CO;2-1

Claus EB, Schildkraut JM, Thompson WD and Risch NJ (1996). The genetic attributable risk of breast and ovarian cancer. 
Cancer 77: 2318-2324. http://dx.doi.org/10.1002/(SICI)1097-0142(19960601)77:11<2318::AID-CNCR21>3.0.CO:2-Z

Crew KD, Gammon MD, Terry MB, Zhang FF, et al. (2007). Polymorphisms in nucleotide excision repair genes, polycyclic aromatic hydrocarbon-DNA adducts, and breast cancer risk. Cancer Epidemiol. Biomarkers Prev. 16: 2033-2041. http:// dx.doi.org/10.1158/1055-9965.EPI-07-0096

Hou R, Liu Y, Feng Y, Sun L, et al. (2014). Association of single nucleotide polymorphisms of ERCC1 and XPF with colorectal cancer risk and interaction with tobacco use. Gene 548: 1-5. http://dx.doi.org/10.1016/i.gene.2014.05.025

Lee KM, Choi JY, Kang C, Kang CP, et al. (2005). Genetic polymorphisms of selected DNA repair genes, estrogen and progesterone receptor status, and breast cancer risk. Clin. Cancer Res. 11: 4620-4626. http://dx.doi.org/10.1158/10780432.CCR-04-2534

Lunn RM, Langlois RG, Hsieh LL, Thompson CL, et al. (1999). XRCC1 polymorphisms: effects on aflatoxin B1-DNA adducts and glycophorin A variant frequency. Cancer Res. 59: 2557-2561.

Martin AM and Weber BL (2000). Genetic and Hormonal Risk Factors in Breast Cancer. J Natl. Cancer Inst. 92: 1126-1135. http://dx.doi.org/10.1093/jnci/92.14.1126

Pei XH, Yang Z, Lv XQ and Li HX (2014). Genetic variation in ERCC1 and XPF genes and breast cancer risk. Genet. Mol. Res. 13: 2259-2267. http://dx.doi.org/10.4238/2014.March.31.6

Popanda O, Schattenberg T, Phong CT, Butkiewicz D, et al. (2004). Specific combinations of DNA repair gene variants and increased risk for non-small cell lung cancer. Carcinogenesis 25: 2433-2441. http://dx.doi.org/10.1093/carcin/bgh264

$<$ bok>Robbins SL, Kumar V and Cotran RS (2010). Robbins and Cotran Pathologic Basis of Disease. Elsevier Saunders, Philadelphia.</bok>

Shen J, Desai M, Agrawal M, Kennedy DO, et al. (2006). Polymorphisms in nucleotide excision repair genes and DNA repair capacity phenotype in sisters discordant for breast cancer. Cancer Epidemiol. Biomarkers Prev. 15: 1614-1619. http:/l dx.doi.org/10.1158/1055-9965.EPI-06-0218

Smith JS, Tachibana I, Pohl U, Lee HK, et al. (2000). A transcript map of the chromosome 19q-arm glioma tumor suppressor region. Genomics 64: 44-50. http://dx.doi.org/10.1006/geno.1999.6101

Yang Z, Fang XD, Pei XH and Li HX (2013). Polymorphisms in the ERCC1 and XPF Genes and Risk of Breast Cancer in a Chinese Population. Genet. Test Mol. Biomarkers 17: 700-706. http://dx.doi.org/10.1089/gtmb.2013.0122

Zhu J, Hua RX, Jiang J, Zhao LQ, et al. (2014). Association studies of ERCC1 polymorphisms with lung cancer susceptibility: a systematic review and meta-analysis. PLoS One 9: e97616. http://dx.doi.org/10.1371/journal.pone.0097616 